\title{
Optimization of Working Bench Length of Inclined Composite Coal Seam Open-Pit Mine
}

\author{
Haoran $\mathrm{Li}^{1}$, Runcai Bai ${ }^{1}$, Guangwei Liu ${ }^{1}$, Han $\mathrm{Du}^{2}$ \\ ${ }^{1}$ Liaoning Technical University, Institute of Mining, Fuxin, Liaoning, China \\ ${ }^{2}$ Department of Hydraulic Engineering, State Key Laboratory of Hydroscience and Engineering, \\ Tsinghua University, Beijing, China \\ *Corresponding Author.
}

\begin{abstract}
In order to optimize the Working bench length of inclined composite coal seam open pit mine, Through theoretical analysis and calculation, the relationship between different mining technology working bench and working face transport costs was studied, The influence of the length of the working bench on the stripping ratio of production and the mining with discharging cost of the unit coal in the mining area were studied. Taking the minimum sum of the transportation cost of working face and the cost of mining and discharging of the unit coal as the goal, a mathematical model is established, which takes the working bench as independent variable, the corresponding function curve was obtained, Considering the macroscopic planning of open-pit mine, obtain an optimization method for the length of economical and reasonable working bench of inclined composite coal seam open pit mine on the basis of technical feasibility. A case study of Heishan opencast coal mine, the Results show that when the length of working bench of the 13-2 coal seam is $0.9 \mathrm{~km}$, the minimum annual cost of mining and discharging and the transportation cost of the open pit mine were the smallest, and the minimum value is 269 million yuan, Considering the actual pit-limit of Heishan open pit mine, it is concluded that the comprehensive optimum line length of 13-2 coal seam in Heishan open-pit mine is 1.0km.
\end{abstract}

Keywords: open pit mine; inclined composite coal seam; length of the working bench; transportation cost on working face; cost of mining and discharging

\section{Introduction}

In open-pit mining, the mining area already prepared for mining, that is, equipped with mining equipment, transportation lines, power supply, etc., is referred to as work line. The work line is divided based on steps and open-pit mines. The work lines discussed in this paper refer to steps. Work line length of the open-pit mine is an important factor that affects the mine's production capacity, economic benefits, and the division of mining areas. The work line length directly determines the mining area width of the open-pit mine, and the mining area width is an important parameter to determine the division of the open-pit mining area. All mine projects must be implemented on the basis of reasonable mining area division, and under small changes in progress, work line length becomes one of the most important factors that determine the output of open-pit mines ${ }^{[1-7]}$. Work line length affects not only the production scale of the open-pit mine, but also the coal cost per ton, which determines the basic economic benefits of the open-pit mine in the next few years or even decades to a considerable extent ${ }^{[8-10]}$. To achieve the same coal mining volume, on the one hand, as the work line length increases, the stripping ratio gradually decreases, the annual stripping volume of the mine decreases, and the annual stripping cost is correspondingly reduced; on the other hand, the transportation system reciprocates transportation operations along the work line. The operating cost of the mining process system relates to the work line length. As the work line length increases, the distance of the stripping and internal drainage transport increases, and the increase in transportation cost leads to an increase in the total cost ${ }^{[11-14]}$. Then, under the same conditions, that is, under the same geological resources, production scale, mining technology and mining procedures, there is definitely an optimal work line length which enables the best economic benefits and the lowest annual production cost of the

ISSN: 0010-8189

(C) CONVERTER 2020

www.converter-magazine.info 
open-pit mine ${ }^{[15-16]}$. Therefore, it is of great significance to determine economical and reasonable work line length for the open-pit mine.

There is not much research by scholars at home and abroad on the optimization of the work line length of the openpit mine, and most researches target at open-pit mines in nearly horizontal or gently inclined coal seams, which do not relate to open-pit mines in inclined composite coal seams ${ }^{[17-20]}$. The author studies the relationship between the work line length of open-pit mine in inclined composite coal seam and the mining, drainage, transportation costs to establish a simple and reliable mathematical model, conducts comprehensive optimization research on reasonable work line length of open-pit mine in inclined composite coal seam under the goal of minimizing the annual mining, drainage and transportation costs of the mine.

\section{Analysis of Working Face Transportation Cost}

According to the different locations of the transportation route, the transportation distance of open-pit mine can be divided into: the working face transportation distance, the end slope transportation distance, the ground transportation distance, and the unloading transportation distance. In coal mining and external drainage operations in a mine, the working face distance depends on the work line length; in internal drainage operations of the mine, both working face distance and unloading distance are related to the work line length. According to the different mining technology systems used in the mine, the working face transportation cost can be divided into working face transportation cost of truck and working face transportation cost of belt conveyor.

\subsection{Transportation cost of working face truck}

Due to the different operating environment, the calculation of truck transportation cost in open-pit mine is different from that of ordinary truck transportation cost. The cost is mainly composed of fuel consumption, maintenance, equipment depreciation, and labor cost. The truck transportation per unit volume of mine can be calculated by the following formula:

$$
C_{K}=C_{\mathrm{r}}\left(L_{k \mathrm{~g}} C_{S}+H_{g} C_{h}\right)+C_{k b}+C_{k r}+C_{K z}
$$

Where: $C_{\mathrm{K}}$-truck transportation cost per unit volume of material, yuan $/ \mathrm{m}^{3}$;

$C_{\mathrm{r}}$ - unit price of truck fuel consumption, yuan/t;

$L_{\mathrm{kg}}$ - horizontal haul distance of truck working face, $\mathrm{km}$;

$C_{\mathrm{S}}$ - fuel consumption per unit volume of minerals in horizontal transportation, $\mathrm{t} /\left(\mathrm{m}^{3} \cdot \mathrm{km}\right)$;

$H_{\mathrm{g}}$ - the vertical lifting height difference of truck working face, m;

$C_{\mathrm{h}}$ - fuel consumption per unit volume of mineral transportation at vertical elevation, $\mathrm{t} /\left(\mathrm{m}^{3} \cdot \mathrm{m}\right)$;

$C_{\mathrm{kb}}$ - The cost of consumable parts per unit volume of mineral in truck transportation, yuan $/ \mathrm{m}^{3}$;

$C_{\mathrm{kr}}$ - The labor cost per unit volume of minerals in truck transportation, yuan $/ \mathrm{m}^{3}$;

$C_{\mathrm{kz}}$ - depreciation cost per unit volume of minerals in truck transportation, yuan $/ \mathrm{m}^{3}$;

When the spoil of the open-pit mine is transported by truck, the horizontal distance of the working face in truck transportation can be expressed as:

$$
L_{k g}=L_{g} / 2
$$

Where: $L_{\mathrm{g}}$ - work line length, m;

When the spoil in the open-pit mine adopts the single-wing internal drainage by trucks, both the working face haul distance and unloading haul distance are related to the work line length, as shown in Figure 1, then horizontal haul distance of the working face is:

ISSN: 0010-8189

$$
L_{k g}=L_{\mathrm{g}}
$$




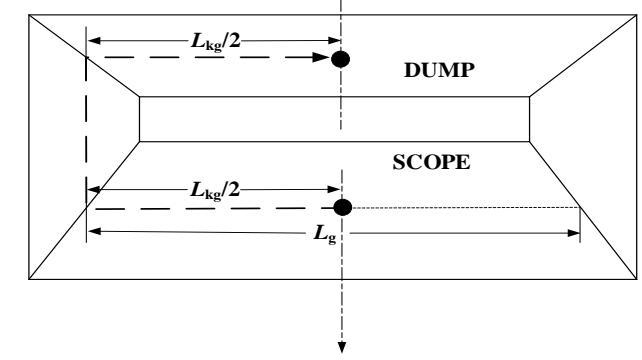

Fig 1: Single row inner dumping transportation of open pit mine

When the spoil of the open-pit mine adopts the double-wing internal drainage by trucks, the working face haul distance and unload haul distance are also related to the work line length, as shown in Figure 2, then horizontal haul distance of the working face is:

$$
\mathrm{L}_{\mathrm{kg}}=\mathrm{L}_{\mathrm{g}} / 2
$$

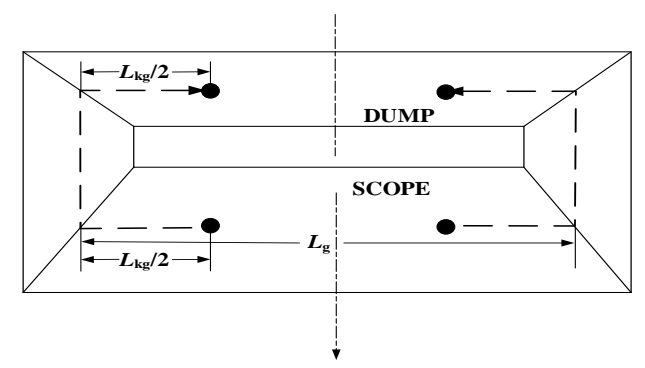

Fig 2: Double row inner dumping transportation of open pit mine

Formulas 2.1, 2.2, 2.3, and 2.4 show that, for open-pit mine, the horizontal haul distance and transportation cost of working face truck increase with the increase of work line length.

\subsection{Transportation cost of working face belt conveyor}

The transportation cost of the working face belt conveyor is mainly composed of four parts: electricity cost, accessory cost, labor cost and equipment depreciation. The electricity cost is positively related to the length of the working face belt conveyor, and the equipment depreciation is negatively related to the working face length.

The cost per unit volume of ore and rock transported by the working face belt conveyor is calculated according to formula 2.5:

$$
C_{J}=\frac{P_{J *} C_{d}}{3600 S * v}+C_{J P}+C_{J R}+C_{J Z}
$$

Where, $C_{\mathrm{J}}$ - the cost per unit volume of material transported by the belt conveyor, yuan $/ \mathrm{m}^{3}$;

$P_{\mathrm{J}}$-motor power of belt conveyor, $\mathrm{kW}$;

$C_{\mathrm{d}}$ - unit price of electricity for belt conveyor, yuan/(kW•h);

$S$-The cross-sectional area of the material on the conveyor belt, $\mathrm{m}^{2}$;

$v$-Conveyor belt speed, $\mathrm{m} / \mathrm{s}$;

$C_{\mathrm{JP}}$-Spare parts cost per unit volume of material, yuan $/ \mathrm{m}^{3}$;

$C_{\mathrm{JR}}$ - labor cost per unit volume of material, yuan $/ \mathrm{m}^{3}$;

$C_{\mathrm{JZ}}$ - equipment depreciation cost per unit volume of material, yuan $/ \mathrm{m}^{3}$. 
The motor power of the belt conveyor is determined by formula 2.6:

$$
P_{J}=v \frac{C\left\{f L_{s} g\left[q_{R O}+q_{R U}+\left(2 q_{B}+Q_{m} / 3.6 v\right) \cos \delta\right]\right\}+F_{\varepsilon}+F_{g 1}+F_{r}+F_{p}+Q_{m} H_{d} g / 3.6 v}{1000 \eta}
$$

Where: $C$-additional coefficient of resistance;

$f$-simulated friction coefficient;

$L s$ - the length of the working surface belt conveyor, $L_{\mathrm{s}}=L_{\mathrm{g}}, \mathrm{m}$;

$q_{\mathrm{RO}}$ - The rotating part mass of the idler of the belt conveyor carrying branch per meter of machine length, $\mathrm{kg} / \mathrm{m}$;

$q_{\mathrm{RU}}$ - the rotating part mass of the idler of the belt conveyor return branch per meter of machine length, $\mathrm{kg} / \mathrm{m}$;

$q_{\mathrm{B}}$ - the mass of the conveyor belt per meter, $\mathrm{kg} / \mathrm{m}$;

$Q_{\mathrm{m}}$-Designed conveying capacity of belt conveyor, $\mathrm{t} / \mathrm{m}$;

$H_{\mathrm{d}}$ - lifting height difference of belt conveyor, m;

$g$-acceleration of gravity, $9.81 \mathrm{~m} / \mathrm{s}^{2}$;

$\delta$-The inclination angle of the belt conveyor in the running direction, ${ }^{\circ}$;

$F_{\varepsilon}$-additional frictional resistance of the forward-tilt idler, N;

$F_{\mathrm{g} 1}$-The frictional resistance between the conveyed material and the feed channel, N;

$F_{\mathrm{r}}$-Friction resistance of conveyor belt cleaner, N;

$F_{\mathrm{p}}$-Friction resistance of the plough tripper, N;

$\eta$-The transmission efficiency from the brake wheel to the transmission drum.

In the process system using working face belt conveyor, the belt conveyor needs to be moved at a certain step after extraction of every mining belt. During the movement period, the mining technology system ceases operations. Therefore, under constant capacity of mining equipment and performance parameters of auxiliary equipment (such as revered loader, etc.), the shorter working line means more frequent relative movement of the belt conveyor, longer system stop time, and smaller annual production capacity. However, the continuous and semi-continuous process system using working face belt conveyor requires a large equipment investment. Since the equipment has a fixed depreciation period and the annual depreciation cost of the crushing and transportation system is fixed, the smaller system production capacity means higher crushing and transportation system depreciation cost of materials per unit volume, leading to higher overall freight; on the contrary, the overall freight is lower. Therefore, the equipment depreciation cost per unit volume of material is:

$$
C_{s z}=\frac{F_{S z}}{N_{s f} Q_{s e}}\left(1+\frac{P_{s g} T_{s y}}{L_{s}}\right)
$$

Where: $F_{\mathrm{sz}}$ - total investment in crushing transportation system, yuan;

$N_{\text {sf }}$-system service life, a;

$Q_{\mathrm{se}}$ - The annual rated production capacity of the system, $\mathrm{m}^{3} / \mathrm{a}$;

$P_{\mathrm{sg}}$ - the advancing speed of the mining equipment along the work line during the movement period, $\mathrm{m} / \mathrm{day}$;

$T_{\text {sy }}$ - time consumption of working face belt conveyor per single move, day.

In summary, the operating cost of the working face belt conveyor in transporting unit volume of materials first decreases and then increases with the increase of work line length. 


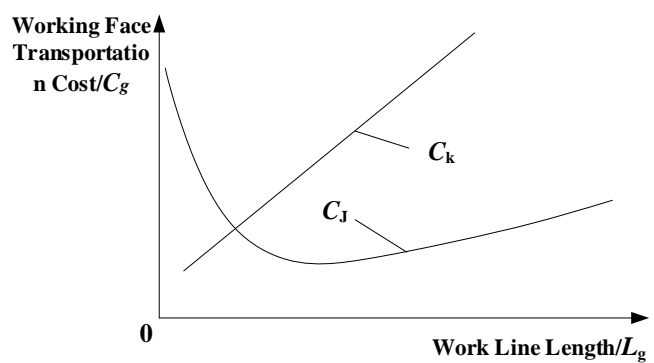

Fig 3: Curve of working surface transportation cost of different mining system in distinct length of working line

According to the above analysis of working face transportation cost, regarding open-pit mines with different mining technology systems, the working face transportation cost change with the work line length is shown in Figure 3. Due to the different mining technology systems, different changing trends in working face transportation costs with work line length are observed. Therefore, the work line length of the open-pit mine needs to be calculated and determined in view of corresponding mining technology system based on specific parameters.

\section{Determination of reasonable work line length}

\subsection{Technically feasible work line length}

Under the premise of constant mine geological engineering conditions and personnel and equipment efficiency, the technically feasible work line length of an open-pit mine can be expressed as:

$$
L_{g}=A_{P} /\left(h \cdot L_{T} \cdot \eta \cdot \gamma\right)
$$

Where, $h$ - the average thickness of the coal seam, m;

$L_{\mathrm{T}}$-open-pit mine advancement degree, m/year;

$\eta$-coal recovery rate, $\%$;

$\gamma$-The bulk density of coal, $\mathrm{t} / \mathrm{m}^{3}$.

Where, advancement speed of the working slope needs to be determined according to the mining technology adopted for the mine in light of actual condition of the specific project.

\subsection{Economical and reasonable work line length}

\subsubsection{The cost of mining and drainage per unit of coal in open-pit mining}

The stope section of an inclined composite coal seam perpendicular to the advancing direction of the working slope is shown in Figure 4. From top to bottom, there are covering layer $B_{1}$, coal seam $A_{1}$, covering layer $B_{2}$, and coal seam $A_{3}$. Suppose the open pit working slope advances $L_{\mathrm{T}}$ meters every year, the working face layout adopts horizontal stratification. The average value of the maximum horizontal distance and minimum horizontal distance of $A_{2}$ coal on the working surface (that is, the work line length of $A_{2}$ coal seam) is defined as the open pit work line length $L_{\mathrm{g}}$. Then:

$$
L_{g}=(A B+C D) / 2
$$

Suppose the coal width of $A_{2}$ at the pit bottom is $L_{1}$, then the lower part length of coal $A_{1}$, covering layer $B_{1}$ and covering layer $B_{2}$ can be expressed as the sum of $L_{1}$ and a fixed value $L_{\mathrm{A} 1}, L_{\mathrm{B} 1}, L_{\mathrm{B} 2}$, respectively, and the length varies with the change of $L_{1}$. 


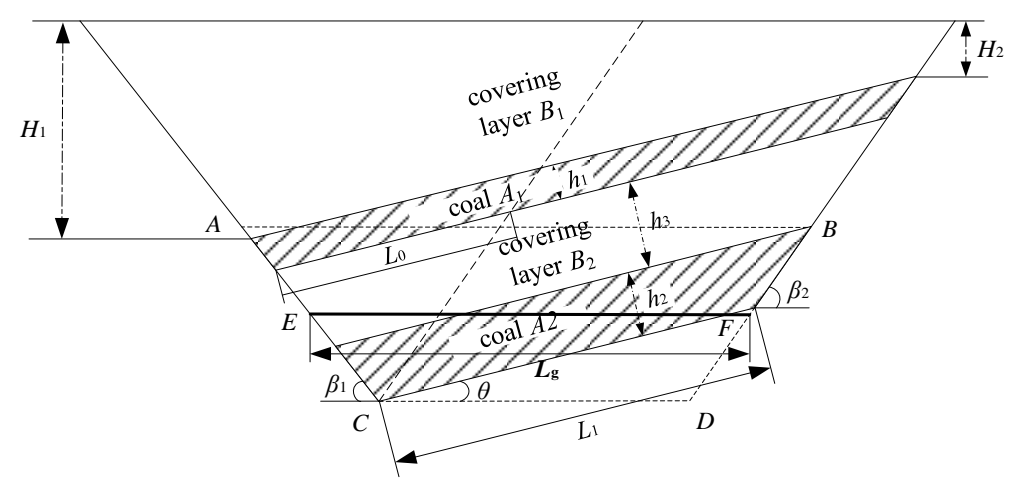

Fig 4: The section perpendicular to the working face of the inclined and composite coal seam open pit mine

Let $\cot \left(\beta_{2}-\theta\right)+\cot \left(\beta_{1}+\theta\right)=a$, then $L_{\mathrm{A} 1}, L_{\mathrm{B} 1}, L_{\mathrm{B} 2}$ are respectively equal to:

$$
\begin{gathered}
L_{A 1}=a\left(h_{2}+h_{3}\right) \\
L_{B 1}=a\left(h_{1}+h_{2}+h_{3}\right) \\
L_{B 2}=a h_{2}
\end{gathered}
$$

Where: $h_{1}-A_{1}$ coal seam thickness, m;

$h_{2}-A_{2}$ coal seam thickness, m;

$h_{3}-B_{2}$ layer covering thickness, $\mathrm{m}$;

$\beta_{1} 、 \beta_{2}$-the slope angle of both slopes, $\left(^{\circ}\right)$;

$\theta$-The coal seam inclination angle, $\left({ }^{\circ}\right)$.

According to the law of sine:

$$
L_{\mathrm{g}}=\frac{L_{1} \sin \left(\beta_{2}-\theta\right) \sin \beta_{1}}{2 \sin \beta_{1} \sin \beta_{2}}+\frac{\left(L_{1}+a h_{2}\right) \sin \left(\beta_{1}+\theta\right) \sin \beta_{2}}{2 \sin \beta_{1} \sin \beta_{2}}
$$

In the same way, the work line lengths of coal $A_{1}$, covering layer $B_{1}$ and covering layer $B_{2}$ are:

$$
\begin{gathered}
L_{\mathrm{A} 1 \mathrm{~g}}=\frac{\left[L_{1}+a\left(h_{2}+h_{3}\right)\right] \sin \left(\beta_{2}-\theta\right) \sin \beta_{1}}{2 \sin \beta_{1} \sin \beta_{2}}+\frac{\left[L_{1}+a\left(h_{1}+h_{2}+h_{3}\right)\right] \sin \left(\beta_{1}+\theta\right) \sin \beta_{2}}{2 \sin \beta_{1} \sin \beta_{2}} \\
L_{\mathrm{B} 1 \mathrm{~g}}=\frac{2\left[L_{1}+a\left(h_{1}+h_{2}+h_{3}\right)\right] \sin \left(\beta_{2}-\theta\right) \sin \beta_{1}}{2 \sin \beta_{1} \sin \beta_{2}}+\frac{H_{1}\left(\cot \beta_{1}+\cot \beta_{2}\right) \sin \beta_{1} \sin \beta_{2}}{2 \sin \beta_{1} \sin \beta_{2}} \\
L_{\mathrm{B} 2 \mathrm{~g}}=\frac{\left[L_{1}+a\left(h_{2}+h_{3}\right)\right] \sin \left(\beta_{1}+\theta\right) \sin \beta_{2}}{2 \sin \beta_{1} \sin \beta_{2}}+\frac{\left(L_{1}+a h_{2}\right) \sin \left(\beta_{2}-\theta\right) \sin \beta_{1}}{2 \sin \beta_{1} \sin \beta_{2}}
\end{gathered}
$$

The annual stripping volume of the open-pit mine consists of two parts: the stripping volume $V_{\mathrm{B} 1}$ of $B_{1}$ covering layer and the stripping volume $V_{\mathrm{B} 2}$ of $B_{2}$ covering layer. $V_{\mathrm{B} 1}$ and $V_{\mathrm{B} 2}$ are respectively equal to:

$$
\begin{gathered}
V_{B 1}=\frac{\left(H_{1}^{2} \cot \beta_{1}+H_{2}^{2} \cot \beta_{2}\right) L_{T}}{2}+\frac{\left(H_{1}+H_{2}\right) \cos \theta\left(L_{1}+L_{A 1}+a \mathrm{~h}_{1}\right) L_{T}}{2} \\
V_{B 2}=\frac{\left(2 L_{1}+L_{A 1}+a \mathrm{~h}_{2}\right) h_{3}}{2} L_{T}
\end{gathered}
$$

Where, $V_{\mathrm{B} 1}$ - stripping volume of $B_{1}$ covering layer, $\mathrm{m}^{3}$;

$V_{\mathrm{B} 2^{-}}$stripping volume of $B_{2}$ covering layer, $\mathrm{m}^{3}$;

ISSN: 0010-8189

www.converter-magazine.info 
$H_{1}, H_{2}$ - The thickness of spoils at both ends of $A_{1}$ coal, m;

$L_{\mathrm{g}}$ - work line length of $A_{2}$ coal, m;

$h_{1}-A_{1}$ coal seam thickness, $\mathrm{m}$.

Then, the annual mine stripping volume $V$ is:

$$
V=\frac{\left(H_{1}+H_{2}\right) \cos \theta\left(L_{1}+L_{A 1}+a h_{1}\right) L_{T}}{2}+\frac{\left(H_{1}^{2} \cot \beta_{1}+H_{2}^{2} \cot \beta_{2}\right) L_{T}}{2}+\frac{\left(2 L_{1}+L_{A 1}+a h_{2}\right) h_{3} L_{T}}{2}
$$

The annual coal production is the sum of the coal production of each coal seam, of which the coal production of $A_{1}$ is:

$$
A_{1}=\frac{\left[2\left(L_{1}+L_{A 1}\right)+a h_{1}\right]}{2} h_{1} L_{T}
$$

$A_{2}$ coal production is:

$$
A_{2}=\left(L_{1}+\frac{a h_{2}}{2}\right) h_{2} L_{T}
$$

The sum of $A_{1}$ and $A_{2}$ coal production is:

$$
A=\left[\frac{2 L_{1}\left(h_{1}+h_{2}\right)+a\left(h_{1}^{2}+h_{2}^{2}\right)+2 L_{A 1} h_{1}}{2}\right] L_{T}
$$

According to formulas 3.12 and 3.15, calculate the stripping ratio in open-pit mine production:

$$
n_{s}=\frac{H_{1}^{2} \cot \beta_{1}+H_{2}^{2} \cot \beta_{2}}{2 L_{1}\left(h_{1}+h_{2}\right)+a\left(h_{1}^{2}+h_{2}^{2}\right)+2 L_{A 1} h_{1}}+\frac{\left(H_{1}+H_{2}\right) \cos \theta\left(L_{1}+L_{A 1}+a h_{1}\right)}{2 L_{1}\left(h_{1}+h_{2}\right)+a\left(h_{1}^{2}+h_{2}^{2}\right)+2 L_{A 1} h_{1}}+\frac{\left(2 L_{1}+L_{A 1}+a h_{2}\right) h_{3}}{2 L_{1}\left(h_{1}+h_{2}\right)+a\left(h_{1}^{2}+h_{2}^{2}\right)+2 L_{A 1} h_{1}}
$$

Where: $n_{\mathrm{s}}$ - the stripping ratio in open-pit mine production, $\mathrm{m}^{3} / \mathrm{m}^{3}$.

From formulas 3.6 and 3.16, the relationship between the production stripping ratio and the work line is shown in Figure 5. From the figure, it can be seen that the stripping ratio ns in open-pit mine production first decreases with the increase of work line length $\mathrm{Lg}$, and then gradually stabilizes. The cost of mining and drainage per unit of coal mining also first decreases with it and then gradually stabilizes.

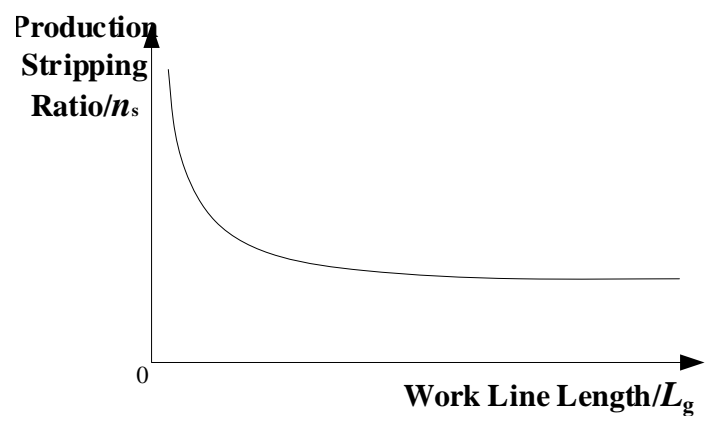

Fig 5: Curve of production stripping ratio with working bench length

Suppose the unit mining and drainage price of soil and rock spoils per $\mathrm{m}^{3}$ and coal is $C_{1}$ and $\mathrm{C}_{2}$ yuan respectively, the annual ore and rock mining and drainage cost per unit of coal in the open-pit mine can be expressed by the following formula: 


$$
F_{C}=\frac{\left(H_{1}^{2} \cot \beta_{1}+H_{2}^{2} \cot \beta_{2}\right) C_{1} A_{P}}{2 L_{1}\left(h_{1}+h_{2}\right)+a\left(h_{1}^{2}+h_{2}^{2}\right)+2 L_{A 1} h_{1}}+\frac{\left(H_{1}+H_{2}\right) \cos \theta\left(L_{1}+L_{A 1}+a h_{1}\right) C_{1} A_{P}}{2 L_{1}\left(h_{1}+h_{2}\right)+a\left(h_{1}^{2}+h_{2}^{2}\right)+2 L_{A 1} h_{1}}+\frac{\left(2 L_{1}+L_{A 1}+a h_{2}\right) h_{3} C_{1} A_{P}}{2 L_{1}\left(h_{1}+h_{2}\right)+a\left(h_{1}^{2}+h_{2}^{2}\right)+2 L_{A 1} h_{1}}+A_{P} C_{2}
$$

Where: $F_{\mathrm{C}}$ - the annual ore and rock mining and drainage cost of the open-pit mine, yuan;

$A_{\mathrm{P}}$-Annual production capacity of open-pit mine, $\mathrm{t}$;

$C_{1}, C_{2}$ - The unit mining and drainage price of spoil and coal, yuan $/ \mathrm{m}^{3}$.

\subsubsection{Transportation cost of open-pit mine working face}

Annual working face transportation cost of the open-pit mine in inclined composite coal seam can be expressed by the following formula:

$$
\begin{gathered}
F_{y}= \\
\frac{\left(H_{1}^{2} \cot \beta_{1}+H_{2}^{2} \cot \beta_{2}\right) C_{B 1} A_{P}}{2 L_{1}\left(h_{1}+h_{2}\right)+a\left(h_{1}^{2}+h_{2}^{2}\right)+2 L_{A 1} h_{1}}+\frac{\left(H_{1}+H_{2}\right) \cos \theta\left(L_{1}+L_{A 1}+a h_{1}\right) C_{B 1} A_{P}}{2 L_{1}\left(h_{1}+h_{2}\right)+a\left(h_{1}^{2}+h_{2}^{2}\right)+2 L_{A 1} h_{1}}+\frac{\left(2 L_{1}+L_{A 1}+a \mathrm{~h}_{2}\right) h_{3} C_{B 2} A_{P}}{2 L_{1}\left(h_{1}+h_{2}\right)+a\left(h_{1}^{2}+h_{2}^{2}\right)+2 L_{A 1} h_{1}}+ \\
\frac{\left[2\left(L_{1}+L_{A 1}\right)+a h_{1}\right] h_{1} C_{A 1} A_{P}}{2 L_{1}\left(h_{1}+h_{2}\right)+a\left(h_{1}^{2}+h_{2}^{2}\right)+2 L_{A 1} h_{1}}+\frac{\left(2 L_{1}+a h_{2}\right) h_{2} C_{A 2} A_{P}}{2 L_{1}\left(h_{1}+h_{2}\right)+a\left(h_{1}^{2}+h_{2}^{2}\right)+2 L_{A 1} h_{1}}
\end{gathered}
$$

Where: $F_{\mathrm{y}}$ - annual ore rock face transportation cost of open-pit mine, yuan;

$C_{\mathrm{B} 1}, C_{\mathrm{B} 2}, C_{\mathrm{A} 1}, C_{\mathrm{A} 2}$ - correspond to the unit transportation price $C_{\mathrm{K}}$ of working face truck or unit transportation price $C_{\mathrm{J}}$ of the working face belt conveyor, which changes with the change of the work line length $L_{\mathrm{g}}$, yuan $/ \mathrm{m}^{3}$.

3.2.3 The relationship between the work line length and the sum of annual mining and drainage costs and working face transportation costs

From formulas 3.17 and 3.18, the sum of mining and drainage costs per unit coal and working face transportation costs in open-pit mines can be calculated:

$$
\begin{gathered}
F_{Z}=\frac{\left(H_{1}^{2} \cot \beta_{1}+H_{2}^{2} \cot \beta_{2}\right)\left(C_{1}+C_{B 1}\right) A_{P}}{2 L_{1}\left(h_{1}+h_{2}\right)+a\left(h_{1}^{2}+h_{2}^{2}\right)+2 L_{A 1} h_{1}}+\frac{\left(H_{1}+H_{2}\right) \cos \theta\left(L_{1}+L_{A 1}+a h_{1}\right)\left(C_{1}+C_{B 1}\right) A_{P}}{2 L_{1}\left(h_{1}+h_{2}\right)+a\left(h_{1}^{2}+h_{2}^{2}\right)+2 L_{A 1} h_{1}}+\frac{\left(2 L_{1}+L_{A 1}+a h_{2}\right) h_{3}\left(C_{1}+C_{B 2}\right) A_{P}}{2 L_{1}\left(h_{1}+h_{2}\right)+a\left(h_{1}^{2}+h_{2}^{2}\right)+2 L_{A 1} h_{1}}+ \\
\frac{\left[2\left(L_{1}+L_{A 1}\right)+a h_{1}\right] h_{1} C_{A 1} A_{P}}{2 L_{1}\left(h_{1}+h_{2}\right)+a\left(h_{1}^{2}+h_{2}^{2}\right)+2 L_{A 1} h_{1}}+\frac{\left(2 L_{1}+a h_{2}\right) h_{2} C_{A 2} C_{P}}{2 L_{1}\left(h_{1}+h_{2}\right)+a\left(h_{1}^{2}+h_{2}^{2}\right)+2 L_{A 1} h_{1}}+A_{P} C_{2}
\end{gathered}
$$

Where: $F_{\mathrm{Z}}$ - the sum of annual mining and drainage costs and working face transportation costs in open-pit mine, yuan.

By solving the minimum value of formula 2.219 and substituting it to formula 2.6 , it is possible to calculate the economically optimal work line length of the open-pit mine. On this basis, the actual work line length of the mine can be adjusted accordingly based on the actual situation of the mine's macro planning, overall optimization of the transportation system, and internal drainage planning.

\section{Case study}

The Heishan Open-pit Coal Mine is located in the depths of Tianshan Mountains in Xinjiang. There are two main mining seams 11 and 13-2 from top to bottom in the mine field, with an average thickness of $12 \mathrm{~m}$ and $39 \mathrm{~m}$, respectively. Consisting of inclined coal seams with a big inclination angle $\left(15^{\circ} \theta\right.$ on average), it is a typical openpit mine in inclined composite coal seam. The first mining area of the open-pit mine has been basically mined, and the stripping project will soon be transferred to the western mining area. The annual production capacity of the mine is $10.0 \mathrm{Mt}$, and the bulk density of raw coal is $1.30 \mathrm{t} / \mathrm{m}^{3}$. Both stripping and coal mining adopt the singlebucket-truck process. According to the production experience of the Heishan open-pit mine, its working slope advance speed $L_{\mathrm{T}}$ is between 120 180m/a. By substituting formulas 3.6 and 3.7 into formula 3.1 , the technically feasible work line length of Heishan Open-pit Mine 13-2 coal is between $775 \mathrm{~m} \sim 1211 \mathrm{~m}$. The boundary of the open-

ISSN: 0010-8189 
pit mine is shown in Figure 6, and the stope section perpendicular to the advancing direction of the working slope is shown in Figure 7. The covering thickness at both ends is $H_{1}=185 \mathrm{~m}, H_{2}=42 \mathrm{~m}$, respectively, and the slope angle is $\beta_{1}=35^{\circ}, \beta_{2}=40^{\circ}$, respectively. According to the calculation of the mine cost over the years, $C_{\mathrm{kb}}=0.2$ yuan, $C_{\mathrm{kr}}=0.17$ yuan, $C_{\mathrm{kz}}=0.23$ yuan, the relevant parameters are shown in Table 1 . Submit the parameters in Table 1 into formula 3.19 .

$$
F_{Z}=\frac{10000000\left(0.53 L_{1}^{2}+1742.07 L_{1}+739430.77\right)}{102 L_{g}+15691.68}+1.5 \times 10^{7}
$$

\begin{tabular}{ccccc}
\hline $\begin{array}{c}\text { Tab. } 1 \\
\begin{array}{c}\text { Parameters of coal } \\
\text { and rock strata in }\end{array}\end{array}$ & $\begin{array}{c}\text { work line } \\
\text { length } / \mathrm{m}\end{array}$ & $\begin{array}{c}\text { Average } \\
\text { thickness } \\
/ \mathrm{m}\end{array}$ & $\begin{array}{c}\text { Unit price of mining } \\
\text { and drainage } / \text { yuan }+\mathrm{m}^{-}\end{array}$ & $\begin{array}{c}\text { Transportation unit } \\
\text { price } / \text { yuan } * \mathrm{~m}^{-3}\end{array}$ \\
\hline Covering Layer $B_{1}$ & $0.66 L_{1}+506$ & 109 & 2.12 & $0.62\left(0.66 L_{1}+506\right) / 1000+0.6$ \\
Coal $A_{1}$ & $L_{1}+487$ & 12 & 1.5 & $1.15\left(L_{1}+487\right) / 1000+0.6$ \\
Covering Layer $B_{2}$ & $L_{1}+347$ & 132 & 2.12 & $1.33\left(L_{1}+347\right) / 1000+0.6$ \\
Coal $A_{2}$ & $L_{1}+71$ & 39 & 1.5 & $1.56\left(L_{1}+71\right) / 1000+0.6$ \\
\hline
\end{tabular}

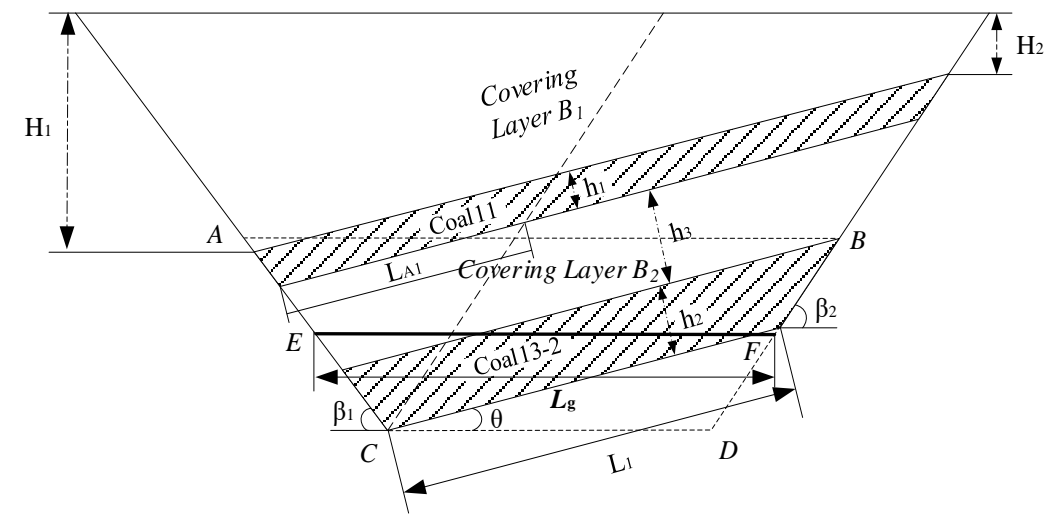

Fig 6: The cross section of the stope in the vertical direction of the Heishan open-pit mine

The function image corresponding to equation 4.1 is shown in Figure 8.

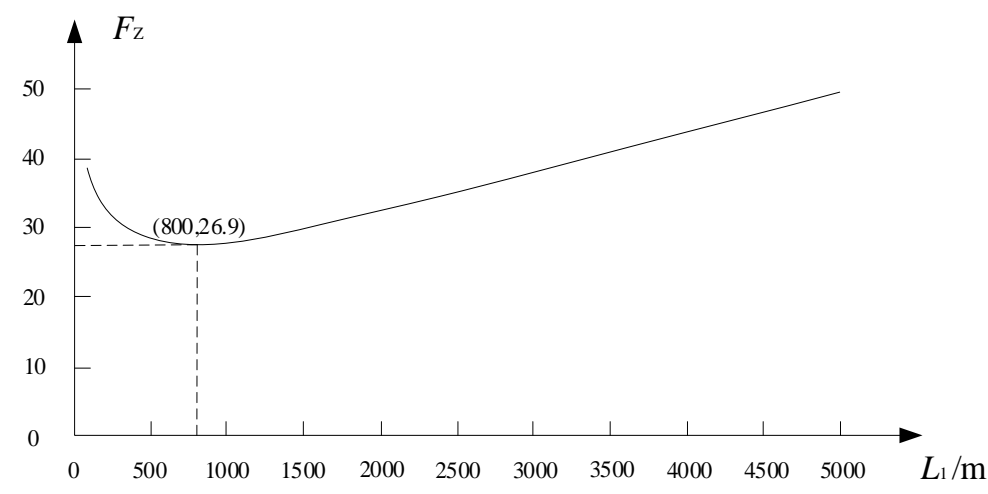

Fig 7: $F_{z}$ varying with $L_{l}$

then:According to the function image, it can be seen that when $L_{1}=0.8 \mathrm{~km}$, the sum of annual mining and drainage costs and working face transportation costsof the open-pit mine is the smallest, with aminimum value of 269 million yuan. Considering the actual pit bottom boundary of the Heishan open-pit mine, verage width of the west pit bottom of the No. 11 exploration line is $0.9 \mathrm{~km}$, so $L_{1}=0.9 \mathrm{~km}$. Substitute $L_{1}=0.9$ into formula 2.6 , then $L_{\mathrm{g}}=1.0 \mathrm{~km}$. At this time, $L_{\mathrm{g}}$ is technically feasible and within the reasonable working face distance range of the car

ISSN: 0010-8189 
(not exceeding 2.0km), which is the optimal work line length of the Heishan open-pit mine. Substitute $L_{1}=0.9$ into equations 3.7, 3.8, and 3.9 respectively, then: regarding the reasonable matching of the work line length of each coal and rock layer in the open-pit mine: the work line length of $B_{1}$ layer spoil is $1.4 \mathrm{~km}$, the work line length of the $11 \mathrm{coal}$ seam is $1.3 \mathrm{~km}$, and the work line length of $B_{2}$ layer spoil is $1.2 \mathrm{~km}$.

\section{Conclusion}

1) The relationship between work line length and working face transportation cost differs much under different mining technology systems. The transportation cost of working face truck increases with the increase of work line length, while the transportation cost of working face belt conveyor first decreases and then increases with the increase of work line length.

2) The relationship between work line length of inclined composite coal seam and the mining and drainage cost per unit of coal mining is analyzed. Under the premise of technical feasibility, to minimize the sum of the mine's annual mining and drainage costs and the working face transportation cost, the study proposes optimization method for economical and reasonable work line length of open-pit mine in inclined composite coal seam.

3) Take Heishan open-pit mine as an example, the $F_{Z}-L_{1}$ relationship curve of the mine is plotted based on calculation, and the reasonable work line length of $13-2$ coal is finally determined to be $1.0 \mathrm{~km}$.

\section{Acknowledgements}

This research was supported by National Natural Science Foundation of China (Grant No. 51974144).

\section{References}

[1] R.X. Zhang, Y.S. Gao, H.H. Li, et al., "Application of hierarchical optimization method for optimization of open pit mining," Journal of China Coal Society, vol. 05, pp. 491-495, 2003.

[2] A.L. Liu, S.L. Wang, et al., "Determination of reasonable mining scheme of AnJiaLing open-pit mining," Coal Science and Technology, vol. 07, pp. 47-49, 2003.

[3] W.Y. Hao, "Theory and application of process system design based on open pit mining machine," China University of Mining and Technology, 2010.

[4] Z.D. Wang, "Study on the location determination and the way of turning in the mining area of open pit coal mine," Coal Science and Technology, vol. 08, pp. 34-39, 2015.

[5] R.C. Bai, E.S. Fu, G.W. Liu, J.L. Qu, "Yet Ming Guo Le reasonable work No. two pit line length optimization of," World science and technology research and development, vol. 03, pp. 365-369, 2013.

[6] X.Q. Liu, "Optimization of sidewall parameters and working line length in open pit combined mining of Antaibao mine,” Beijing University of science and technology, 2008.

[7] R.X. Zhang, X.R. Mei, Y.S. Gao, et al., "Planning and decision making system of open pit mining and its application," Journal of China University of Mining and Technology, vol. 32, no. 3, pp. 270-273, 2003.

[8] L. Ma, K.M. Li, H.G. Peng, X.H. Ding, S.S. Xiao, "Both open pit coal mine down at the bottom of the pile of thin seam mining technology of column," Journal of Mining \& Safety Engineering, under the condition of 2015, vol. 01, pp. 73-77+83.

[9] T. Liu, "Huolinhe No. 1 opencast coal mine mining division and transition optimization of," China University of Mining and Technology, 2016.

[10] D.J. Zhao, X.H. Fu, "Application of semi continuous process of self moving crusher in open pit mine," Opencast Mining Technology, vol. 07, pp. 46-49, 2016.

[11] Z.C. Cai, Z. Wei, H.Z. Li, "Different working line length drop ditch schemes," Coal Engineering, vol. S2, pp. 10-11+14, 2012

[12] Y. Gao, J. Chang, J.Z. Liu, “The real health, safety, large opencast coal mine work line layout research 
of," Coal Mine, vol. 09, pp. 51-54, 2014.

[13] F.M. Liu, S.Z. Chen, Q.X. Cai, W. Zhou, J. Chang, et al., "Determine the middle bypass opencast coal mine application conditions and the key parameters of coal," Journal of China coal society, vol. 01, pp. 73-79, 2015.

[14] H.Z. Zhao, R.X. Zhang, and, selection, "A new method of double dip dynamic stripping mining in open pit coal mine,” Journal of China coal society, vol. 05, pp. 855-860, 2014.

[15] S.F. Zhang, "The reasonable length of mining working line in open pit," open air mining technology, vol. 06, pp. 20+44, 2006.

[16] R.S. Yu, Y.F. Xi, “Journal of optimization of,” line length Chinese open-pit mining, vol. 01, pp. 18-32, 1986.

[17] S.Q. Chen, "Determination of the length of the north section of the open pit coal mine in Shengli east of Datang," Opencast Mining Technology 2014, vol. 12, pp. 56-59.

[18] H.q. Wang, j.z. Li, "Optimization of the length of the working line in Shengli opencast coal mine," Opencast Mining Technology, vol. 03, pp. 11-12+16, 2007.

[19] Z.Y. Yao, T.S. Fu, Z.X. Fan, "Optimization of. surface mining technology, the line length of the openpit mine," Opencast Mining Technology2006, vol. 01, pp. 4-6.

[20] W. Miao, “Opencast coal mine throwing blasting - shovel truck technology working line length optimization of," Coal Science and Technology, vol. 04, pp. 9-11+15, 2014. 